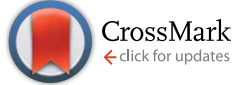

Cite this: RSC Adv., 2016, 6, 60145

\title{
Kinetics and thermodynamics studies for bisphenol $S$ adsorption on reduced graphene oxide
}

\author{
Lingyun $\mathrm{Li}^{\mathrm{a}}{ }^{\mathrm{D}}$ Donghui $\mathrm{Xu}^{\mathrm{a}}$ and Zhiguo $\mathrm{Pei}^{\star \mathrm{b}}$
}

Received 25th April 2016 Accepted 16th June 2016

DOI: 10.1039/c6ra10607b

www.rsc.org/advances
The adsorption behavior of bisphenol S (BPS) on reduced graphene oxide (rGO) was investigated. The adsorption kinetics data are best described with a pseudo-second-order model and the equilibrium data are well fitted by both Freundlich and Langmuir models. The maximum adsorption capacity of BPS on $\mathrm{rGO}$ at $\mathrm{pH} 6.0$ and $T=298 \mathrm{~K}$ was $261.74 \mathrm{mg} \mathrm{g}^{-1}$. It was found that the increase of solution $\mathrm{pH}$ was unfavorable for BPS adsorption due to the increasing electrostatic repulsion between BPS and rGO. The thermodynamics data indicated that the adsorption of BPS on rGO was a spontaneous and exothermic process. Fourier transform infrared (FTIR) spectra suggested that BPS adsorption on rGO was primarily driven by $\pi-\pi$ interaction between the graphene's hexagonal arrays and the aromatic core of BPS. Results from this study demonstrate that $\mathrm{rGO}$ is a promising adsorbent for BPS removal in water treatment.

\section{Introduction}

As an alternative to bisphenol A (BPA), BPS has been widely used in the production of epoxy resins, cyclic carbonates, and thermal receipt papers, and as a chemical additive in pesticides, dyestuffs, color-fast agents, leather tanning agents, flame retardants, and fiber improvers. ${ }^{1}$ Eventually BPS will be inevitably released into the environment. It has been frequently detected in surface water $\left(0-6840 \mathrm{ng} \mathrm{L}^{-1}\right){ }^{2}$ sediments $(0.002-$ $1970 \mathrm{ng} \mathrm{g}^{-1}$ dry weight), ${ }^{3}$ sewage sludge (0.17-110 ng g ${ }^{-1}$ dry weight $),{ }^{4}$ wastes such as human urine, ${ }^{5,6}$ and daily products. ${ }^{7-9}$

However, recent studies revealed that BPS is not a totally safe chemical and could cause similar estrogenic response as BPA. For example, it was found that BPS can induce rapid nongenomic signaling in estrogen-responsive pituitary cells at low (femtomolar to picomolar) concentrations. ${ }^{\mathbf{1 0}}$ Michalowicz et al. suggested that BPS can induce oxidative stress and damage in human peripheral blood mononuclear cells. ${ }^{11}$ In addition, it was found that BPS can also cause obesity and hepatic steatosis processes at low doses that fall in the concentration range found in the environment. ${ }^{12,13}$ Therefore, the production and application of BPS has triggered serious concerns on its potential adverse effects on both the environment and human health. Compared to BPA, BPS is more heat- and light-resistant, and was not found to break down in sea water for a lengthy period, ${ }^{\mathbf{1 4}}$ which suggests that BPS is more resistant to environmental degradation and may possess higher environmental

\footnotetext{
${ }^{a}$ Supervision and Testing Center for Vegetable Quality (Beijing), Ministry of Agriculture, The Institute of Vegetables and Flowers, Chinese Academy of Agricultural Sciences, Beijing, 100081, China

${ }^{b}$ State Key Laboratory of Environmental Chemistry and Ecotoxicology, Research Center for Eco-Environmental Sciences, Chinese Academy of Sciences, PO Box 2871, Beijing 100085, China. E-mail: peizg@rcees.ac.cn; Tel: +86-10-62849329
}

risk. Thus, it is necessary to prevent its release into the environment by removing it from BPS-embedded wastewater before discharge. The conventional removal methods of organic contaminants from water include advanced oxidation, photocatalysis, ${ }^{15}$ electrolysis, ${ }^{16}$ membrane filtration, ${ }^{17}$ and adsorption, ${ }^{\mathbf{1 8} 19}$ etc. However, there are disadvantages associated with the first four methods. For example, advanced oxidation, photocatalysis and electrolysis can result in the formation of unknown and toxic byproducts, if not properly operated. Membrane technology is relatively expensive. Among these approaches, adsorption has been found to be superior to other techniques due to its low-cost, high efficiency and easy operation.

Graphene has a two-dimensional structure with only one atomic thickness, and has attracted considerable attention recently. Due to its large surface area and high ability of modification, graphene-based nanomaterials possess great potentials in the adsorption of pollutants. ${ }^{20}$ For example, graphene oxide (GO), the oxidized form of graphene, consists of abundant surface O-containing functional groups (e.g., carboxyl, hydroxyl, and epoxy groups) on its edges and surfaces, enabling it to adsorb cationic ions and compounds. Previous studies had revealed that GO preferentially adsorbed metal ions and positively charged organic molecules, and was one of the most effective adsorbents for some metal ions, such as $\mathrm{Co}$ (II), $\mathrm{Cd}(\mathrm{II}), \mathrm{Pb}(\mathrm{II}), \mathrm{Cu}(\mathrm{II})$ and $\mathrm{Eu}(\mathrm{III}) .{ }^{21-24}$ In contrast, graphene tends to adsorb and remove organic pollutants, especially for organic pollutants with $\pi$ electrons, thanks to its large surface area and strong hydrophobic graphitic lattice surface. It was found that graphene can adsorb organic chemicals with high adsorption capacity through hydrophobic interactions, ${ }^{25} \pi-\pi$ interaction, ${ }^{26,27}$ hydrogen bond, ${ }^{25}$ electrostatic interactions and Lewis acid-base interaction. ${ }^{28}$ Graphite is essentially made up of 
hundreds to thousands of graphene sheets. However, its interlayer space is very small, and will not be occupied by environmental chemicals. Thus, the adsorption capacity of graphite is much smaller than that of graphene. Although the adsorption of organic contaminants on graphene has been studied extensively, little information is known about the adsorption behavior of BPS on graphene. ${ }^{\mathbf{1 4}}$

In this study, we investigated the adsorption kinetics, isotherms and thermodynamics of BPS on rGO and factors that influenced the adsorption. Understanding of the kinetics and thermodynamics of BPS adsorption on rGO is critical for determining the effect of graphene materials on the fate and transport of BPS and for the design and operation of adsorption equipment. The adsorption rates were evaluated with the pseudo-first-order, and pseudo-second-order equations, and the adsorption isotherms were fitted by Freundlich and Langmuir models.

\section{Experimental and methods}

\subsection{Materials}

BPS (4,4'-sulfonyldiphenol, 99\%) was purchased from J\&K Scientific Ltd. (Shanghai, China), and used as received. Its selected properties are listed in Table $1 . \mathrm{NaCl}, \mathrm{NaOH}$, and $\mathrm{HCl}$ were of guarantee reagent grade. Methanol was of HPLC grade.

rGO was obtained by thermal exfoliation/reduction using graphite oxide as a precursor. ${ }^{29}$ Briefly, graphite powder (10 g) and sodium nitrate $(5 \mathrm{~g})$ were mixed with sulfuric acid $(230 \mathrm{~mL})$ in a beaker in an ice bath, and potassium permanganate $(30 \mathrm{~g})$ was slowly added, and the mixture was kept at $274 \mathrm{~K}$ for $2 \mathrm{~h}$ with continuous agitation. The reaction was kept at $308 \pm 2 \mathrm{~K}$ for $30 \mathrm{~min}$ with gas release, and then $460 \mathrm{~mL}$ of deionized water was gradually added, bringing about violent effervescence. The temperature of the water bath was increased to $371 \mathrm{~K}$ and the reaction was maintained at this temperature for $40 \mathrm{~min}$ in order to increase the oxidation degree of product. The resultant bright-yellow suspension was further treated with $\mathrm{a}_{2} \mathrm{O}_{2}$ solution $(30 \mathrm{~mL}, 30 \%)$ followed by centrifugation and careful washing to clean out remnant salt. The wet graphite oxide was dewatered by vacuum drying at $323 \mathrm{~K}$. rGO was achieved by a thermal expansion under high vacuum. ${ }^{30}$ The above prepared graphite oxide was put into a quartz tube, which was connected to a high vacuum pump. The tube temperature was increased to $1073 \mathrm{~K}$ at a rate of $50 \mathrm{~K} \mathrm{~min}^{-1}$, and kept at this temperature for
$5 \mathrm{~h}$ under a high vacuum $(<1 \mathrm{~Pa})$. After that, the produced rGO sample was obtained.

\subsection{Characterization of rGO}

rGO was characterized by transmission electron microscopy (TEM), scanning electron microscopy (SEM), atomic force microscopy (AFM), Raman spectroscopy, and X-ray photoelectron spectroscopy (XPS). Nitrogen specific surface area of rGO was estimated using an accelerated surface area system and the Brunauer-Emmett-Teller (BET) equation based on the adsorption of $\mathrm{N}_{2}$ at $77 \mathrm{~K}$.

\subsection{Adsorption kinetics}

The adsorption kinetics experiments were carried out at $298 \pm$ $0.5 \mathrm{~K}$ by mixing $1.5 \mathrm{mg}$ rGO with $20 \mathrm{~mL}$ of $0.01 \mathrm{M} \mathrm{NaCl}$ solution containing $10.0 \mathrm{mg} \mathrm{L}^{-1}$ BPS in $40 \mathrm{~mL}$ glass centrifuge tubes sealed with Teflon-lined screw-caps. The suspended solution $\mathrm{pH}$ was adjusted to $6.0 \pm 0.1$ by addition of $0.1 \mathrm{M} \mathrm{HCl}$ or $0.1 \mathrm{M}$ $\mathrm{NaOH}$ to assure BPS present in neutral species during adsorption process. After the samples were shaken end-over-end for predefined periods, the suspensions were filtered through a $0.45 \mu \mathrm{m}$ membrane filter. The concentrations of BPS in the filtrate were determined by HPLC (Agilent 1200). The quantity of BPS adsorbed at time $t, q_{t}\left(\mathrm{mg} \mathrm{g}^{-1}\right)$, was deduced from the mass balance between initial concentration and solution concentration at time $t$. Parallel experiments without rGO addition were prepared and served as control. Result showed no significant loss of BPS (recoveries range from 99-101\%), indicating that microbial degradation, volatilization, or adsorption to the glass walls were negligible during the adsorption experiments.

\subsection{Adsorption experiments}

A batch equilibration adsorption experiment was carried out in triplicate by mixing $1.5 \mathrm{mg}$ of rGO with $20 \mathrm{~mL}$ of $0.01 \mathrm{M} \mathrm{NaCl}$ solution containing a series concentrations of BPS (1.0, 5.0, 10.0, 15.0, 20.0, 30.0, and 50.0 $\mathrm{mg} \mathrm{L}^{-1}$ ) in $40 \mathrm{~mL}$ glass centrifuge tubes sealed with Teflon-lined screw-caps. The pHs of suspended solution were maintained at $6.0 \pm 0.1$ by addition of $0.1 \mathrm{M} \mathrm{HCl}$ or $0.1 \mathrm{M} \mathrm{NaOH}$. The prepared samples were rotated continuously for $24 \mathrm{~h}$ at different temperatures (298 $\pm 0.5,308$ \pm 0.5 , and $318 \pm 0.5 \mathrm{~K}$ ). After equilibrium, the suspensions were filtered, and the concentrations of BPS in the filtrate were determined by HPLC.

Table 1 Selected properties of $\mathrm{BPS}^{a}$

\begin{tabular}{lllll}
\hline Organic chemical & Structures & $\mathrm{MW}(\mathrm{g} \mathrm{mol})$ & $S\left(\mathrm{~g} \mathrm{~L}^{-1}\right)$ & $\log K_{\mathrm{ow}}$ \\
\hline BPS & & & 1.1 & 250.27
\end{tabular}

${ }^{a} \mathrm{MW}$ : molecular weight, $\mathrm{g} \mathrm{mol}^{-1} ; S$ : aqueous solubility at room temperature, $\mathrm{mg} \mathrm{L}^{-1} ; K_{\mathrm{ow}}$ octanol-water partition coefficient; $K_{\mathrm{a}}$, dissociation constant. 
The $\mathrm{pH}$ effect experiment was conducted using a batch adsorption approach as mentioned above. The initial BPS concentration was $10.0 \mathrm{mg} \mathrm{\textrm {L } ^ { - 1 }}$. The $\mathrm{pH}$ was adjusted from 3.0 to 11.0 by addition of $0.1 \mathrm{M} \mathrm{HCl}$ or $\mathrm{NaOH}$. After equilibrium, the final $\mathrm{pH}$ values were measured, and the suspensions were filtered and analyzed for BPS concentrations.

\section{5. $\mu$-FTIR measurements}

$\mu$-FTIR spectra were recorded on NICOLET iN 10 MX (Thermo Scientific). Samples for $\mu$-FTIR analysis were prepared with identical conditions to that used in the adsorption experiments. BPS adsorbed rGO was washed with water, and then freezedried overnight. Microsamples were pressed on a diamond bracket and $\mu$-FTIR spectra were measured. The resolution for FTIR spectra was $4 \mathrm{~cm}^{-1}$, and a total of 100 scans were collected for each spectrum.

\subsection{Analysis}

The concentrations of BPS were determined by HPLC (Agilent 1200) equipped with a UV detector, and an extended polar selectivity reversed-phase C18 column (4.6 i.d. $\times 150 \mathrm{~mm}$, $5 \mu \mathrm{m})$. The determination wavelength was set at $258 \mathrm{~nm}$. Isocratic elution was performed at a flow rate of $1.0 \mathrm{~mL} \mathrm{~min}^{-1}$, the mobile phase was methanol : water $(40: 60, \mathrm{v} / \mathrm{v})$.

\section{Results and discussion}

\subsection{Physicochemical properties of rGO}

The surface morphology of rGO was characterized by TEM and SEM (Fig. 1a and b). It was found that the rGO is closely agglomerated together by thin and randomly aggregated nanosheets, and has a typically wrinkled and sheet-like structure. The BET specific surface area of rGO was determined to be $530 \mathrm{~m}^{2} \mathrm{~g}^{-1}$. The thickness of rGO was measured by AFM (Fig. 1c). The results show that the thickness of rGO is $1.31 \mathrm{~nm}$, corresponding to about 3.8 layers of graphene, which is close to the calculated result (about 5.0 layers of graphene) using the scaling law: layer number $=2600 / A_{\mathrm{BET}}{ }^{31}$

Raman spectra of graphite and rGO are presented in Fig. 1d, which are used to reveal the structural changes during the preparation of rGO from graphite. For graphite, there are two prominent peaks at 1328 and $1574 \mathrm{~cm}^{-1}$, which correspond to the documented $\mathrm{D}$ band and $\mathrm{G}$ band, respectively. ${ }^{30}$ It is well known that the $\mathrm{G}$ band corresponds to first-order scattering of $\mathrm{E}_{2 \mathrm{~g}}$ mode observed for $\mathrm{sp}^{2}$ carbon domains, and the pronounced D band is associated with structural defects, amorphous carbon, or edges that can break the symmetry and selection rule. ${ }^{30}$ When rGO is exfoliated from graphite, spectrum of the rGO showed that the $\mathrm{D}$ band and $\mathrm{G}$ band are broaden and intensity of the $\mathrm{D}$ band increases, which suggests the increase of amorphous carbon and structural defects on the exfoliated graphene sheets.

The FTIR spectra of rGO are shown in Fig. 1e, where peak at $1556 \mathrm{~cm}^{-1}$ is assigned to benzene ring $\mathrm{C}=\mathrm{C}$ stretching vibration, and peaks appeared at 1736 and $1220 \mathrm{~cm}^{-1}$ are the results of carboxyl $\mathrm{C}=\mathrm{O}$ and epoxy $\mathrm{C}-\mathrm{O}$ stretching vibrations,

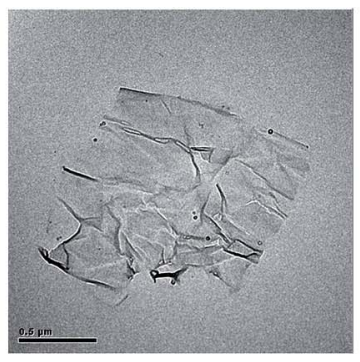

(a)

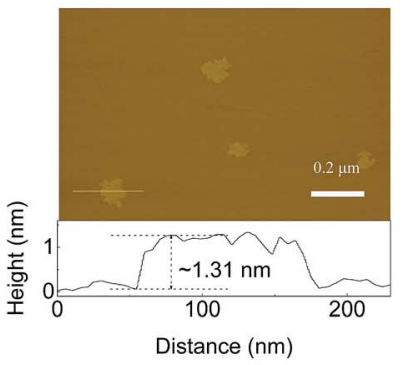

(c)

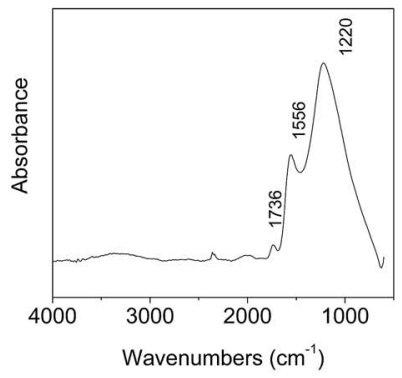

(e)

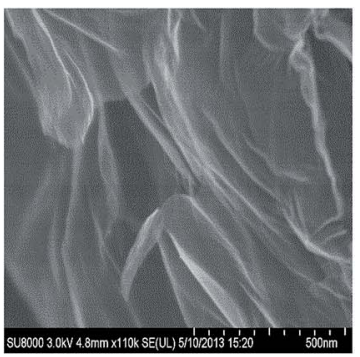

(b)

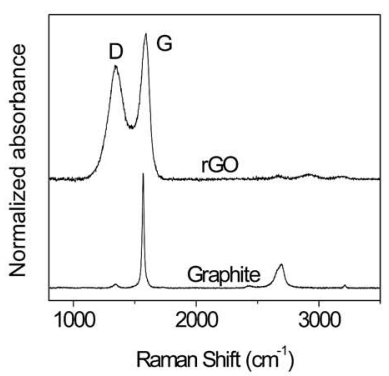

(d)

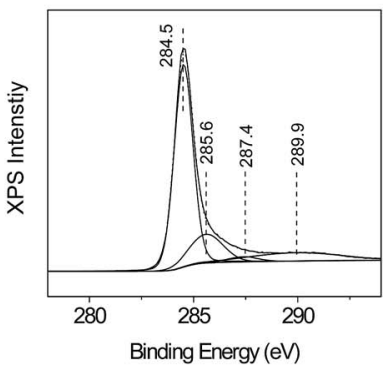

(f)
Fig. 1 Characterization of rGO: (a) TEM image; (b) SEM image; (c) AFM image; (d) Raman spectra; (e) FTIR spectrum; (f) XPS spectrum.

respectively. This indicates that some O-containing functional groups are included on the outermost surface and defect sites of rGO.

XPS further provides useful information on the nature of functional groups on rGO. In Fig. If the XPS C1s spectrum of rGO is presented. Deconvolution of the C1s peak resolved a main peak of $\mathrm{sp}^{2} \mathrm{C}=\mathrm{C}(284.5 \mathrm{eV})$ and several small peaks of the carbon in $\mathrm{C}-\mathrm{O}(285.6 \mathrm{eV})$, the carbonyl carbon in $\mathrm{C}=\mathrm{O}$ $(287.4 \mathrm{eV})$, and the epoxy group in $\mathrm{C}(\mathrm{O}) \mathrm{O}(289.9 \mathrm{eV})$. The oxygen content of the rGO is low $(9.0 \%$ as determined by elemental analysis; C/O ratio of 10.0, as determined by XPS). The oxygen is mostly in the form of hydroxyl (5.23\%), followed by epoxy (3.01\%) and carbonyl groups $(1.0 \%)$, according to XPS results. The epoxy and hydroxyl groups may be located at the basal planes, in the interior of the aromatic domains, while the carbonyl group could be located at the edges of the sheets or at the edges of holes.

\subsection{Effect of pH on adsorption}

Solution pH plays a critical role in the adsorption of BPS because it may cause the dissociation of BPS and affect the surface net charge of rGO. Therefore the adsorption of BPS on 


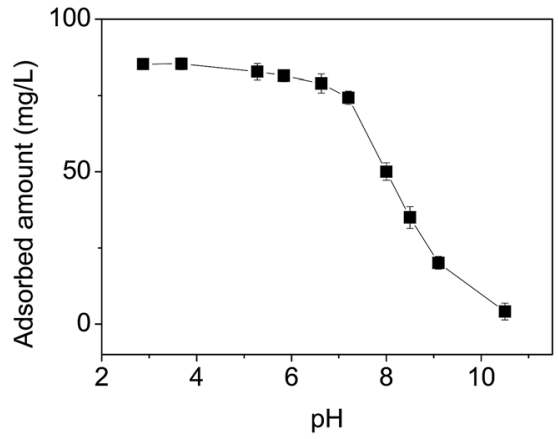

Fig. 2 Effect of equilibrium solution $\mathrm{pH}$ on the adsorption of BPS on rGO. Data are means of three separate experiments. Errors bars represent standard deviation.

rGO as a function of solution $\mathrm{pH}$ was investigated (Fig. 2). It can be seen that in acidic $\mathrm{pH}$ ranges from 3.0 to 7.0 the adsorption capacity of rGO showed little change, remained at around $83.0 \mathrm{mg} \mathrm{g}^{-1}$. With an increase of solution $\mathrm{pH}$ above 7.0, the adsorption capacity declined sharply to about $4.0 \mathrm{mg} \mathrm{g}^{-1}$ at $\mathrm{pH}$ 10.5. This phenomenon can be explained by the net charge of rGO and the species of BPS at different pHs. In our previous study, ${ }^{32}$ it was shown that the electrophoretic mobilities of rGO were negative over the examined $\mathrm{pH}$ range, which suggests that the surface of rGO is negatively charged. Considering a $\mathrm{p} K_{\mathrm{a}}$ value of 8.2, ${ }^{14} \mathrm{BPS}$ presents mainly in neutral form at $\mathrm{pH}<7.0$. As solution $\mathrm{pH}$ increases, more BPS was deprotonated, the adsorption capacity of BPS on rGO decreases due to the repulsion between the negatively charged surface of rGO and deprotonated BPS.

\subsection{Adsorption kinetics}

Fig. 3 presents the adsorption of BPS on rGO versus contact time. It is found that the adsorption amount of BPS increased dramatically, and reached maximum within only $0.18 \mathrm{~h}$, suggesting that the adsorption of BPS on rGO is a fast process. On the basis of the above result, a contact time of $12 \mathrm{~h}$ was selected for the following adsorption experiments to ensure complete equilibrium.

To investigate the mechanism of the adsorption process, two conventional kinetic models (pseudo-first-order eqn (1) and pseudo-second-order eqn (2)) were used to analyze the experimental data.

$$
\begin{gathered}
\ln \left(q_{\mathrm{e}}-q_{t}\right)=\ln q_{\mathrm{e}}-k_{1} t \\
\frac{t}{q_{t}}=\frac{1}{k_{2} q_{\mathrm{e}}^{2}}+\frac{1}{q_{\mathrm{e}}} t
\end{gathered}
$$

where $q_{\mathrm{e}}\left(\mathrm{mg} \mathrm{g}^{-1}\right)$ and $q_{t}\left(\mathrm{mg} \mathrm{g}^{-1}\right)$ are the concentrations of BPS adsorbed on rGO at equilibrium and at time $t, k_{1}\left(\mathrm{~h}^{-1}\right)$ is the rate constant of eqn (1) for adsorption, $k_{2}\left(\mathrm{~g} \mathrm{mg}^{-1} \mathrm{~h}^{-1}\right)$ is the rate constant of eqn (2) for adsorption. The values of $q_{\mathrm{e}}$ and $k_{1}$ can be calculated from the intercept and the slope of the linear plot of $\ln \left(q_{\mathrm{e}}-q_{t}\right)$ versus $t$ for eqn (1). Furthermore, the slope and intercept of the linear plot of $t / q$ against $t$ yielded the values of $1 /$ $q_{\mathrm{e}}$ and $1 / k_{2} q_{\mathrm{e}}^{2}$.
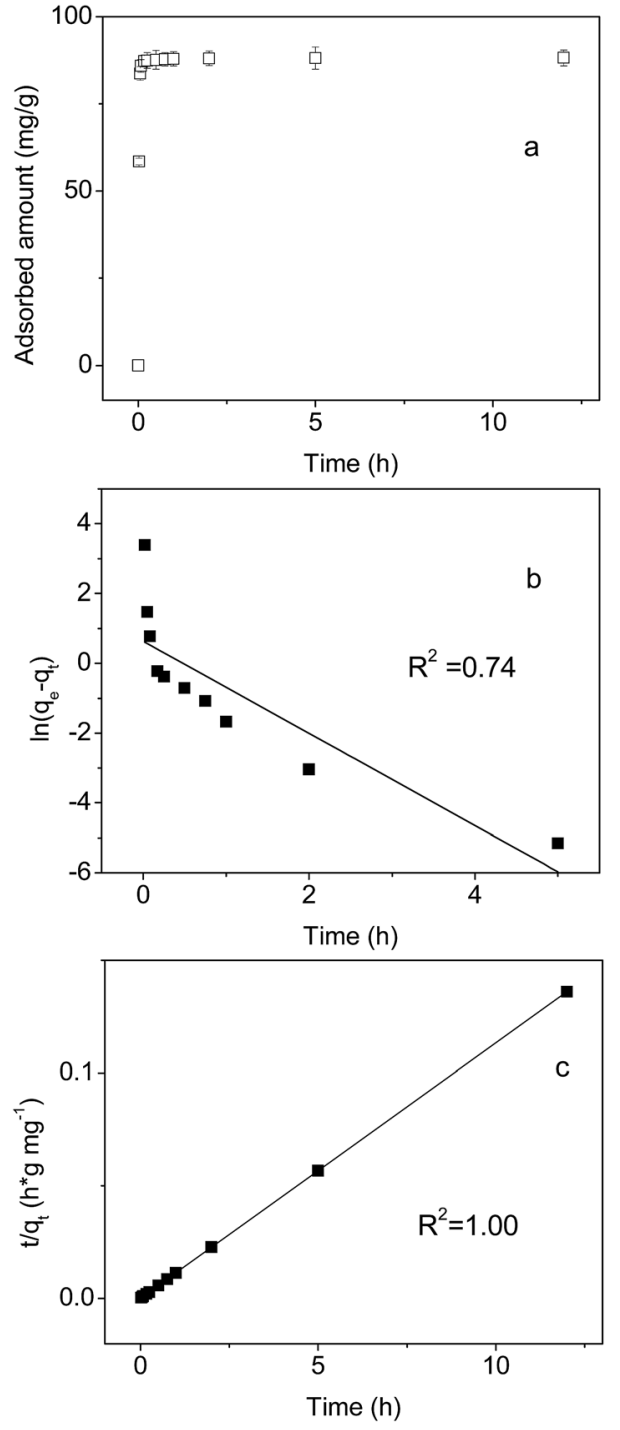

Fig. 3 (a) Effect of contact time on BPS adsorption rate $(\mathrm{pH}=6.0, T=$ $298 \mathrm{~K}$ ); (b) test of pseudo first-order rate equation for the adsorption of BPS by rGO; (c) test of pseudo second-order rate equation for the adsorption of BPS by rGO.

The fitted kinetic parameters of the two models were listed in Table 2. It is shown that the correlation coefficient $R^{2}$ of pseudofirst-order equation is only 0.74 , and the equilibrium adsorption capacity, $q_{\mathrm{e}}$, derived from the equation is $1.89 \mathrm{mg} \mathrm{g}^{-1}$, which is much lower than the measured equilibrium adsorption amount $\left(88.10 \mathrm{mg} \mathrm{g}^{-1}\right)$. Therefore, the pseudo-first-order equation is not a good fit for BPS adsorption on rGO. The

Table 2 Coefficients of kinetic model regression (BPS concentration

\begin{tabular}{|c|c|c|c|c|c|}
\hline Pseudo-first & rder mod & & Pseudo-seco & $\mathrm{d}$ order model & \\
\hline$q_{\mathrm{e}}\left(\mathrm{mg} \mathrm{g}^{-1}\right)$ & $k_{1}\left(\mathrm{~h}^{-1}\right)$ & $R^{2}$ & $q_{\mathrm{e}}\left(\mathrm{mg} \mathrm{g}^{-1}\right)$ & $k_{2}\left(\mathrm{mg} \mathrm{g}^{-1} \mathrm{~h}^{-1}\right)$ & $R^{2}$ \\
\hline 1.89 & 1.32 & 0.74 & 88.20 & 2.90 & 1.00 \\
\hline
\end{tabular}
of $10 \mathrm{mg} \mathrm{L}^{-1}, \mathrm{pH}=6.0$ ) 
experimental data are instead fitted by the pseudo-second-order model. Results show that the correlation coefficient $R^{2}$ value for the pseudo-second-order model is 1 . Furthermore, the calculated adsorption capacity $\left(88.20 \mathrm{mg} \mathrm{g}^{-1}\right)$ from the pseudosecond-order model is also closer to the experimental adsorption capacity $\left(88.10 \mathrm{mg} \mathrm{g}^{-1}\right)$. These results indicate that the experimental data can be better described by the pseudosecond-order model than by the pseudo-first-order model. According to previous studies, ${ }^{33,34}$ the pseudo-second-order model assumes that the rate-limiting step is the chemical binding process involving sharing or exchange of electrons between adsorbent and adsorbate. Therefore, successful fitting of the data with the pseudo-second-order kinetic model also suggests that chemisorption was the rate-controlling step. ${ }^{34}$

\subsection{Adsorption isotherms}

Fig. 4a shows the adsorption isotherms of BPS on rGO at temperature of 298, 308 and $318 \mathrm{~K}$. These adsorption isotherms were fitted by both the Langmuir model eqn (3) and Freundlich model eqn (4).

$$
\begin{aligned}
\frac{C_{\mathrm{e}}}{q_{\mathrm{e}}} & =\frac{1}{K_{\mathrm{L}} q_{\mathrm{m}}}+\frac{C_{\mathrm{e}}}{q_{\mathrm{m}}} \\
q_{\mathrm{e}} & =K_{\mathrm{F}} C_{\mathrm{e}}{ }^{1 / n}
\end{aligned}
$$

where $K_{\mathrm{L}}$ is the Langmuir constant; $q_{\mathrm{m}}$ is the maximum adsorption capacity $\left(\mathrm{mg} \mathrm{g}^{-1}\right)$ and $q_{\mathrm{e}}$ is the amount of BPS adsorbed at equilibrium $\left(\mathrm{mg} \mathrm{g}^{-1}\right), K_{\mathrm{F}}$ and $n$ are Freundlich constants related to the adsorption capacity and adsorption intensity, respectively.

The regression parameters calculated from the Langmuir and Freundlich models at three different temperatures are listed in Table 3. It is shown that the correlation coefficient $R^{2}$ is at the range of 0.99 to 1.0 for Langmuir model and of 0.98 to 0.99 for Freundlich model, indicating that these adsorption data can be fitted well by both models. In Fig. 4a, all adsorption isotherms are highly nonlinear, suggesting that instead of hydrophobic interaction, it is some specific interactions driving BPS adsorption on rGO. According to previous research, ${ }^{25,35-37}$ $\pi-\pi$ electron donor-acceptor interaction between aromatic ring of adsorbates and rGO surface is the main mechanism
Table 3 Parameters for Langmuir and Freundlich models of BPS adsorption on $\mathrm{rGO}$

\begin{tabular}{lllllllll}
\hline & \multicolumn{2}{l}{ Langmuir model } & & \multicolumn{2}{l}{ Freundlich model } \\
\cline { 2 - 3 } Experimental conditions & $q_{\mathrm{m}}$ & $K_{\mathrm{L}}$ & $R^{2}$ & & $K_{\mathrm{F}}$ & $n$ & $R^{2}$ \\
\hline$T=298 \mathrm{~K}$ & 261.74 & 0.12 & 0.99 & 48.40 & 0.44 & 0.99 \\
$T=308 \mathrm{~K}$ & 240.60 & 0.09 & 1.00 & 36.13 & 0.47 & 0.98 \\
$T=318 \mathrm{~K}$ & 236.50 & 0.05 & 1.00 & 20.86 & 0.56 & 0.99
\end{tabular}

responsible for strong adsorption of these adsorbates on rGO. The Langmuir model assumes that adsorption occurs on a homogeneous surface by monolayer coverage and each interaction is independent. Thus, successful fitting of these data with the Langmuir model indicates that the adsorbed BPS formed a monolayer coverage on the rGO surface. As shown in Table 3, the predicted maximum adsorption capacity of BPS on rGO at $298 \mathrm{~K}$ is $261.74 \mathrm{mg} \mathrm{g}^{-1}$, thanks to the large specific surface area of rGO. We further compared the adsorption capacity of rGO for BPS with a commercial activated carbon (data no shown). It is shown that the predicted maximum adsorption capacity of BPS is $61.5 \mathrm{mg} \mathrm{g}^{-1}$ on activated carbon, which was much lower than that on rGO. Thus, rGO is a very efficient adsorbent for the removal of BPS from wastewater.

Considering the potential ecological risk of the residual rGO, ${ }^{38-41}$ we further determined the amount of rGO in filtrate after adsorption using UV-vis technique (data no shown). ${ }^{\mathbf{4 2}}$ Results showed that the filtrate was clean and almost no rGO was observed. It is mainly because that graphene tends to undergo layer-to-layer aggregation in water due to its hydrophobic surface, and can be separated easily after adsorption. Therefore, this adsorption method is considered reliable for BPS removal.

\subsection{Adsorption thermodynamics study}

The effect of temperature on BPS adsorption is presented in Fig. 4a. It is shown that the adsorption amount for BPS decreases with the rise of reaction temperature, indicating that the adsorption reaction is exothermic. A set of thermodynamic parameters, including the standard free-energy change $\left(\Delta G^{0}\right)$,
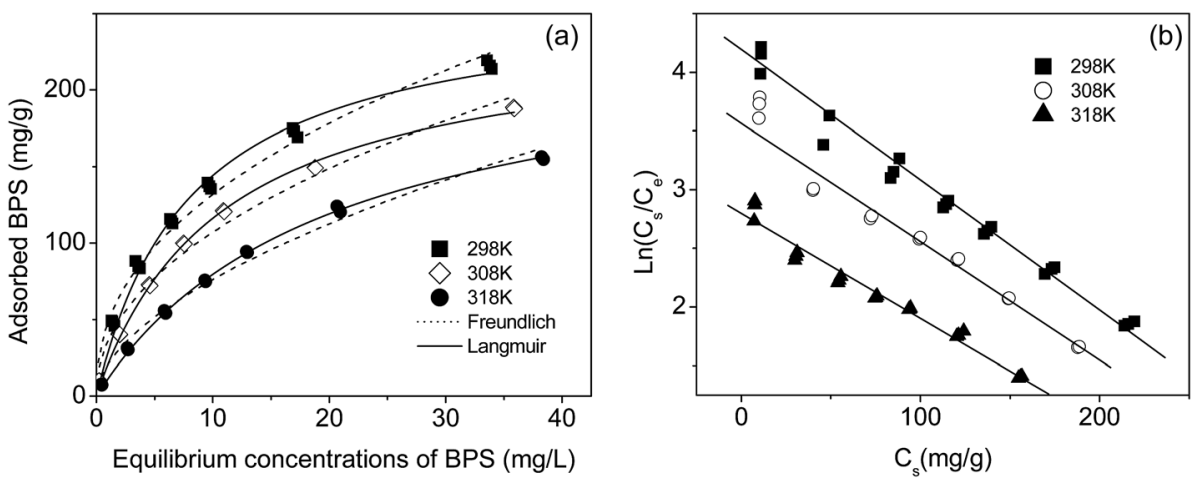

Fig. 4 Adsorption isotherms of BPS on rGO at different temperatures (a); plots of $\ln \left(C_{\mathrm{s}} / C_{\mathrm{e}}\right)$ vs. $C_{\mathrm{s}}$ at different temperatures (b). 
Table 4 Thermodynamic parameters on the adsorption of BPS by rGO

\begin{tabular}{llll}
\hline Temperature $(\mathrm{K})$ & 298 & 308 & 318 \\
\hline $\ln K_{0}$ & 4.19 & 3.57 & 2.80 \\
$\Delta G_{0}\left(\mathrm{~kJ} \mathrm{~mol}^{-1}\right)$ & -10.38 & -9.14 & -7.40 \\
$\Delta H_{0}\left(\mathrm{~kJ} \mathrm{~mol}^{-1}\right)$ & -54.76 & -54.76 & -54.76 \\
$\Delta S_{0}\left(\mathrm{~J} \mathrm{~mol}^{-1} \mathrm{~K}^{-1}\right)$ & -148.93 & -148.12 & -148.93
\end{tabular}

the standard enthalpy change $\left(\Delta H^{0}\right)$, and the standard entropy change $\left(\Delta S^{0}\right)$, are calculated from the temperature-dependent adsorption isotherms. $\Delta G^{0}$ was calculated from the following equation:

$$
\Delta G^{0}=-R T \ln K_{0}
$$

where $R$ is the universal gas constant $\left(8.314 \mathrm{~J} \mathrm{~K}^{-1} \mathrm{~mol}^{-1}\right)$, and $T$ is the temperature in Kelvin. $K_{0}$ is defined using a method described by Niwas et al. ${ }^{43}$ in eqn (6):

$$
K_{0}=\frac{\alpha_{\mathrm{s}}}{\alpha_{\mathrm{e}}}=\frac{v_{\mathrm{s}} C_{\mathrm{s}}}{v_{\mathrm{e}} C_{\mathrm{e}}}
$$

where $\alpha_{\mathrm{s}}$ is the activity of adsorbed BPS, $\alpha_{\mathrm{e}}$ is the activity of BPS in solution at equilibrium, $C_{\mathrm{s}}\left(\mathrm{mg} \mathrm{g}^{-1}\right)$ is the amount of BPS adsorbed by per mass of $\mathrm{rGO}$, and $C_{\mathrm{e}}\left(\mathrm{mg} \mathrm{L}^{-1}\right)$ is BPS concentration in solution at equilibrium, $v_{\mathrm{s}}$ is the activity coefficient of the adsorbed BPS, and $v_{\mathrm{e}}$ is the activity coefficient of BPS in solution. As BPS concentration in solution decreases and approaches to zero, $K_{0}$ can be obtained by plotting $\ln \left(C_{\mathrm{s}} / C_{\mathrm{e}}\right) v s$. $C_{\mathrm{s}}$, and extrapolating $C_{\mathrm{s}}$ to zero (Fig. $4 \mathrm{~b}$ ). The straight line obtained is fitted to the points based on a least-squares analysis. Its intercept with the vertical axis gives the values of $K_{0}$.

The $\Delta H^{0}$ and $\Delta S^{0}$ were calculated from the following equation:

$$
\ln K^{0}=\frac{\Delta S^{0}}{R}-\frac{\Delta H^{0}}{R T}
$$

The slope and intercept of the plot of $\ln K^{0} v s .1 / T$ are $\Delta H^{0} / R$ and $\Delta S^{0} / R$, respectively.

The calculated thermodynamic parameters are given in Table 4. The negative $\Delta H^{0}$ suggested that the interaction of BPS on rGO was an exothermic process, which was consistent with the decreased adsorption capacity of BPS with the increase of temperatures. Three $\Delta G^{0}$ values at different temperatures were negative, implying that the adsorption of BPS on rGO was spontaneous and thermodynamically favorable. And the value of $\Delta G^{0}$ became more negative with the decrease of temperature, indicating that lower temperature facilitated the adsorption of BPS on rGO. The negative $\Delta S^{0}$ implied the reducing mobility of BPS due to surface adsorption.

\section{6. $\quad \mu$-FTIR analysis}

To reveal the adsorption mechanisms of BPS on rGO, a $\mu$-FTIR study was performed. The $\mu$-FTIR spectra of $\mathrm{rGO}$, rGO with adsorbed BPS, and BPS were shown in Fig. 5. For rGO, the peak

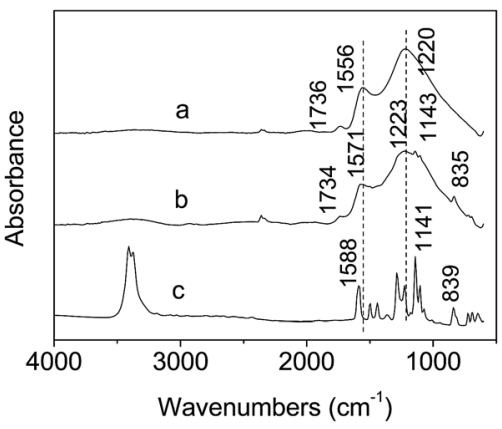

Fig. $5 \mu$-FTIR spectra of rGO (a), rGO after BPS adsorption (b), and BPS (c).

at $1556 \mathrm{~cm}^{-1}$ was assigned to benzene ring $\mathrm{C}=\mathrm{C}$ stretching vibration. And peaks appeared at 1736 and $1220 \mathrm{~cm}^{-1}$ were the results of carboxyl $\mathrm{C}=\mathrm{O}$ and epoxy $\mathrm{C}-\mathrm{O}$ stretching vibrations, respectively. After BPS adsorption, it is found that many new peaks were introduced into the FTIR spectrum of rGO (Fig. 5b). These new peaks were in accordance with the peaks of BPS (Fig. 5c), indicating that BPS had been adsorbed on the surface of rGO. Compared with the spectrum of rGO, it is shown that the peak attributable to the $\mathrm{C}=\mathrm{C}$ stretching vibration shifted from 1556 to $1571 \mathrm{~cm}^{-1}$, suggesting the occurrence of $\pi-\pi$ interaction between the benzene ring of BPS and rGO. The conclusion is consistent with previous studies, ${ }^{25}$ where $\pi-\pi$ interaction was the main driving force for the adsorption of organic pollutants with $\mathrm{C}=\mathrm{C}$ double bonds or aromatic rings on graphene. Besides, rGO also included some residual Ocontaining groups on its surfaces and edges during the reduction process. It is possible that these O-containing groups further interacted with the hydroxyl groups of BPS to form $\mathrm{H}$ boding. However, our FTIR data showed that the adsorption of BPS caused the slight shifts of the carboxyl $\mathrm{C}=\mathrm{O}$ and epoxy $\mathrm{C}-\mathrm{O}$ stretching vibrations of $\mathrm{rGO}$ from 1736 and $1220 \mathrm{~cm}^{-1}$ to 1734 and $1223 \mathrm{~cm}^{-1}$, respectively. Considering the resolution of $\mu$-FTIR, such slight shifts could not be used as a solid evidence for H-bonding formation. Therefore, the BPS adsorption on rGO was primarily driven by $\pi-\pi$ interaction between the graphene surface and the aromatic core of BPS.

\section{Conclusions}

The adsorption kinetics, thermodynamics and isotherms of BPS on rGO were studied. It is shown that the adsorption of BPS on rGO is a fast process, and the kinetics follows a pseudo-second order model, suggesting that chemisorption is the rate-limited step. The adsorption isotherms of BPS on rGO were well described by both the Langmuir and Freundlich models. The large adsorption capacity of rGO implied that rGO is a promising adsorbent for BPS. The calculated thermodynamic parameters showed that BPS adsorption on rGO was exothermic and spontaneous. FTIR results suggested that the BPS adsorption on $\mathrm{rGO}$ was primarily driven by $\pi-\pi$ interaction between the graphene surface and the aromatic core of BPS. 


\section{Acknowledgements}

This work was funded by National Natural Science Foundation of China (grant number: 21477145 and 21277159) and the China Scholarship Council (201504910091). We also thank Dr Rixiang Huang in Georgia Institute of Technology for help with editing this manuscript.

\section{References}

1 S. Changkhamchom and A. Sirivat, Polym. Bull., 2010, 65, 265-281.

2 E. Yamazaki, N. Yamashita, S. Taniyasu, J. Lam, P. K. Lam, H. B. Moon, Y. Jeong, P. Kannan, H. Achyuthan and N. Munuswamy, Ecotoxicol. Environ. Saf., 2015, 122, 565-572.

3 C. Y. Liao, F. Liu, H. B. Moon, N. Yamashita, S. Yun and K. Kannan, Environ. Sci. Technol., 2012, 46, 11558-11565.

4 S. J. Song, M. Y. Song, L. Z. Zeng, T. Wang, R. Z. Liu, T. Ruan and G. B. Jiang, Environ. Pollut., 2014, 186, 14-19.

5 C. Y. Liao, F. Liu, H. Alomirah, V. D. Loi, M. A. Mohd, H. B. Moon, H. Nakata and K. Kannan, Environ. Sci. Technol., 2012, 46, 6860-6866.

6 J. Xue, Q. Wu, S. Sakthivel, P. V. Pavithran, J. R. Vasukutty and K. Kannan, Environ. Res., 2015, 137, 120-128.

7 C. Y. Liao and K. Kannan, J. Agric. Food Chem., 2013, 61, 4655-4662.

8 C. Y. Liao and K. Kannan, Arch. Environ. Contam. Toxicol., 2014, 67, 50-59.

9 C. Y. Liao, F. Liu and K. Kannan, Environ. Sci. Technol., 2012, 46, 6515-6522.

10 R. Viñas and C. S. Watson, Environ. Health Perspect., 2013, 121, 352-358.

11 J. Michalowicz, K. Mokra and A. Bąk, Toxicol. In Vitro, 2015, 29, 1464-1472.

12 C. H. Toussaint, L. Peyre, C. Costanzo, M. C. Chagnon and R. Rahmani, Toxicol. Appl. Pharmacol., 2014, 280, 224-235.

13 M. C. Chagnon, L. Moral, L. Corre and R. Rahmani, Toxicol. Lett., 2015, 238, 22-26.

14 H. Y. Guo, N. Liang, F. Y. Chen, S. H. Liao, D. Zhang, M. Wu and B. Pan, Environ. Sci. Pollut. Res., 2016, 23, 8976-8984.

15 Y. Ide, Y. Nakasato and M. Ogawa, J. Am. Chem. Soc., 2010, 132, 3601-3604.

16 P. Zuman and J. Ludvík, Electroanalysis, 2000, 12, 879-888.

17 V. Yangali-Quintanilla, S. K. Maeng, T. Fujioka, M. Kennedy and G. Amy, J. Membr. Sci., 2010, 362, 334-345.

18 W. Chen, L. Duan, L. Wang and D. Q. Zhu, Environ. Sci. Technol., 2008, 42, 6862-6868.

19 L. Q. Wang, T. Liang, P. J. A. Kleinman and H. Y. Cao, Chemosphere, 2011, 85, 1075-1079.

20 S. Chowdhury and R. Balasubramanian, Adv. Colloid Interface Sci., 2014, 204, 35-56.
21 S. T. Yang, Y. L. Chang, H. F. Wang, G. G. Liu, S. Chen, Y. W. Wang, Y. F. Liu and A. N. Cao, J. Colloid Interface Sci., 2010, 351, 122-127.

22 G. X. Zhao, J. X. Li, X. M. Ren, C. L. Chen and X. K. Wang, Environ. Sci. Technol., 2011, 45, 10454-10462.

23 X. J. Deng, L. L. Lv, H. W. Li and F. Luo, J. Hazard. Mater., 2010, 183, 923-930.

24 C. J. Madadrang, H. Y. Kim, G. H. Gao, N. Wang, J. Zhu, H. Feng, M. Gorring, M. L. Kasner and S. F. Hou, ACS Appl. Mater. Interfaces, 2012, 4, 1186-1193.

25 Z. G. Pei, L. Y. Li, L. X. Sun, S. Z. Zhang, X. Q. Shan, S. Yang and B. Wen, Carbon, 2013, 51, 156-163.

26 J. Xu, L. Wang and Y. F. Zhu, Langmuir, 2012, 28, 8418-8425.

27 J. Wang, Z. M. Chen and B. L. Chen, Environ. Sci. Technol., 2014, 48, 4817-4825.

28 L. Li, W. Chen, Z. Xu, S. R. Zheng and D. Q. Zhu, J. Environ. Qual., 2013, 42, 191-198.

29 C. M. Chen, Q. H. Yang, Y. G. Yang, W. Lv, Y. F. Wen, P. X. Hou, M. Z. Wang and H. M. Cheng, Adv. Mater., 2009, 21, 3007-3011.

30 C. M. Chen, Q. Zhang, M. G. Yang, C. H. Huang, Y. G. Yang and M. Z. Wang, Carbon, 2012, 50, 3572-3584.

31 F. Guo, M. Creighton, Y. T. Chen, R. Hurt and I. Külaots, Carbon, 2014, 66, 476-484.

32 S. Yang, L. Y. Li, Z. G. Pei, C. M. Li, X. Q. Shan, B. Wen and S. Z. Zhang, Carbon, 2014, 75, 227-235.

33 Y. Nuhoglu and E. Malkoc, Bioresour. Technol., 2009, 100, 2375-2380.

34 Y. H. Li, Q. J. Du, T. H. Liu, J. K. Sun, Y. H. Wang, S. L. Wu, Z. H. Wang, Y. Z. Xia and L. H. Xia, Carbohydr. Polym., 2013, 95, 501-507.

35 G. X. Zhao, L. Jiang, Y. D. He, J. X. Li, H. L. Dong, X. K. Wang and W. Hu, Adv. Mater., 2011, 23, 3959-3963.

36 G. X. Zhao, J. X. Li and X. K. Wang, Chem. Eng. J., 2011, 173, 185-190.

37 T. Wu, X. Cai, S. Z. Tan, H. Y. Li, J. S. Liu and W. D. Yang, Chem. Eng. J., 2011, 173, 144-149.

38 Y. L. Zhao, Q. L. Wu and D. Y. Wang, Biomaterials, 2016, 79, 15-24.

39 T. Mesaric, K. Sepcic, V. Piazza, C. Gambardella, F. Garaventa, D. Drobne and M. Faimali, Chemoecology, 2013, 29, 643-652.

40 S. Q. Zhao, Q. Q. Wang, Y. L. Zhao, Q. Rui and D. Y. Wang, Environ. Toxicol. Pharmacol., 2015, 39, 145-156.

41 L. Chen, P. Hu, L. Zhang, S. Huang, L. Luo and C. Huang, Sci. China: Chem., 2012, 55, 2209-2216.

42 N. W. Pu, C. A. Wang, Y. M. Liu, Y. Sung, D. S. Wang and M. D. Ger, J. Taiwan Inst. Chem. Eng., 2012, 43, 140-146.

43 R. Niwas, U. Gupta, A. A. Khan and K. G. Varshney, Colloids Surf., A, 2000, 164, 115-119. 